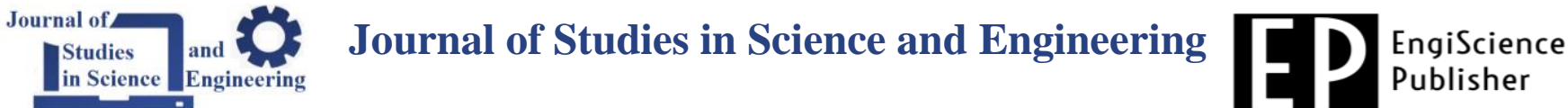

\section{Covid-19 and Functionality: By Providing Social Distancing of Indoor Common Spaces in Residential Building}

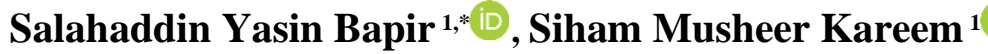 \\ ${ }^{1}$ Department of Architecture, College of Engineering, Salahaddin University-Erbil, Erbil, 44002, Iraq \\ *Corresponding Author: Salahaddin Yasin Bapir, E-mail: salahaddin.baper@su.edu.krd
}

\begin{abstract}
Article Info
Article History

Received Aug 20, 2021

Revised Aug 28, 2021

Accepted Aug 30, 2021

Keywords

COVID-19

Functionality

Indoor common spaces

Social Distancing

Space syntax

Abstract

Before the COVID-19 pandemic, people spent on average around 90\% of their time indoors. Nowadays, more than ever, with work-from-home commands in place, it is important that they rethink the design and procedure of buildings. Indoor common space parameters straight affect the comfort and well-being of occupants. After COVID-19 cooperates, occupants are at increased danger for many infections make worse by social distancing.

The aim of this study, to assess how to provide social distancing by evaluating the functionality of the plan type on the common indoor spaces in the multi-story apartment buildings in Erbil City.

The methodology in this study integrating quantitative and qualitative approaches to increase the accuracy of the research results. This study chose ten different floor plan types of multistory apartment buildings established on space syntax (software design) analysis, and one primary syntactical indicator is visual connectivity. This research study responds to two questions that discover the effects of functionality in indoor common spaces to provide social distancing of residents.

The results determined that the layout design of the apartment space influences the social distancing of areas. Therefore, the results preferred the single-loaded corridor (gallery) plan over other types to provide social distancing post-COVID-19. The research establishes a foundation for future design and offers visions for new study instructions besides findings.
\end{abstract}

Copyright: (C) 2021 EngiSciece Publisher All rights reserved

\section{Introduction}

A multifunctional space can be described as a proper integration of different functions in time and space [1], the general organization of functions, dimensions, and conversed by the shapes. The whole design depends on the suitability of diverse systems that make up the building, which is productive, comprising the distributive plan or spatial organization, access instruments, and the connection with the outside world [2].

The configuration and position of spaces depending on the determination of the building, followed by the architectural program. The design of the spatial organization, finding a proper preparation of 
functional basics according to particular purposes and restrictions, is essential at practically every scale of architectural practice. This task is compound, studies multiple standards, and is regularly vague [3]. Building circulation is a critical establishing tool of layout and statement space as it links exterior and interior areas and replicates the total spatial organization of the building.

The spatial design and circulation of the changing facilities are ineffectively evaluated from the pathological aspects of social distancing. New developments of the COVID-19 outbreak reveal the facilities are among the highly susceptible public spaces for spreading infections on a large scale. Therefore, the spatial organization and circulation of the building design on the users' agreement to social distancing is the primary way to control the spread of infections in the community [4]. It is to ensure safe processes during the actions of a pandemic by social distancing. The spatial arrangement can be quantitatively measured on the wayfinding scale achieved by the space syntax analysis in architecture. Comparatively, these features commonly appear to be ideal in wayfinding compared to the grid-based and circular-based design [5-6].

Thus, circulation reveals powerfully how designs of space and configuration affect users done actions. Existing methods for circulation planning are based on analyses of the physical abilities of different user groups. Spatial configuration affects human association currents (the behavior of people moving through space and their decisions)[7]. Numerous inquiries in spatial perception pointed to the impact of arrangement organization on both wayfinding presentation and users' cognitive representation of real-world spatial information [8-12]. Nevertheless, there is still a gap in the connection between architectural circulation design and users' ease of wayfinding.

Wayfinding refers to information systems that guide people through a physical environment and enhance their understanding and experience of the space [13]. This is mainly concerned with signage and information systems to assist pedestrians and residents in directing the moving system more effectively and safely with their special tests.

The only problem to the linear corridor, which develops difficulty to social distancing, is the uncertain incurable points due to the nature of the centralized linear plan, which establishes a sense of persistence. Unlike linear planning, grid planning has more dead ends [5]. It is to preserve social distancing under this design situation; the corridor should be used in a single direction to avoid crossover temporarily. Meanwhile, 
the corridor spreads on both sides of the building facing the field and the car park; it is optional to use the car park corridor for entry into the centrally arranged rooms. Wayfinding determines the connectivity or integration in space management between the users, spaces or zones, and the available programs. The wayfinding analysis assesses the performance of spatial connectivity even for the most segregated areas in spatial planning [14]. Social distancing is effective because it "avoids or decreases contact between individuals who may carry or be susceptible to pathogens that are commutable and contagious" [15]. The indoor public spaces commonly found in multi-story residential buildings are divided into five categories in this study which are ( Ground-level open public spaces, Entrance halls, Stairs, Corridors, and Elevators).

The noticeable potential significance of COVID-19 is a worldwide aversion to huge crowds. Concerts, cultural occasions, ceremonials, mass gatherings, daily activities, and political complaints involve many people, commonly in common indoor spaces, such as ground-level open public areas, entrance halls, staircases, corridors, and lifts. These indoor spaces (inside the building) for crowds and activities will be applied to controlling the spread of COVID-19. Through the quarantine, people were said to practice social distancing and to stay home every time possible. However, the World Health Organization (WHO)[16] examination of the spread of COVID-19 in the world showed that $78 \%$ to $85 \%$ of transmission happens inside families. One concern connected to this is disinfection when inhabitants reappearance from outdoor the home. Furthermore, the multi-story apartment residential building includes many different plan types that may provide an additional indoor common space in apartment buildings. Therefore, according to the situation observed above, the research problem can be expressed as verifying the relationship between the architectural plan types of multi-story residential buildings and limiting the spread of COVID-19 in its common indoor spaces[17].

This study aims to estimate how to provide social distancing by the plan type on the common indoor spaces in the multi-story apartment buildings in Erbil City. To reach this purpose, the following aims are stated:

- To define the best design layout type for providing social distancing in multi-story residential buildings.

- To recognize the optimal indicators within the indoor spaces of multi-story apartment residential buildings.

- There are two research questions based on the aims stated above: 
- Which factor has the best typology plan design for providing social distancing?

Which optimal indicators of functionality within the indoor spaces of multi-story apartment residential buildings.

\section{Materials and Methods}

The analysis used mixed methodologies, integrating quantitative and qualitative approaches, to increase the accuracy of the research results. The theoretical framework is chosen using the qualitative approach. Meanwhile, the quantitative method is used for testing the research aims and research questions. In general, the research methodology is managed through four stages listed below:

1. In the first stage, to describe a theoretical model, previous related studies were reviewed. As a result, the research model developed consists of three parameters of indoor common space factors: functionality (spatial organization, wayfinding, and circulation).

2. In the second stage, a qualitative case study is selected using a phenomenological methodology that involves findings, photographs, and documentation[18].

3. In the third stage, classification of case studies according to typology (layout design) consists of (point, single loaded -corridor (Gallery), mixed, double-loaded -corridor, and large scale development (segment)).

4. In the fourth stage, using space syntax as a measurement tool in this study and syntactic analysis of the spatial organization of the research case study is used to support the result of the first stage, in this study using the indicator of VGA map visual connectivity to measuring functionality. After analyzing all case studies by applying visual connectivity indicators due to numerical results as shown in Table 1 .

\section{Results and Discussions}

\subsection{Results obtained from space syntax analysis}

In this study, the Depth Map X10 application from space syntax theory is using as a measurement tool for evaluating the two research questions, measuring indoor common spaces factors, including functionality (wayfinding, spatial organization, and circulation) parameters. Consequently, the Visibility Graph Analysis (VGA) map and visual connectivity were essential measurements implemented over the case study. VGA analysis resulted in two types of research: numeric and visual results based on a color graph. 


\section{Data collection}

\section{Theoretical model}

\section{Select case study}

\section{Classification of Case study} according to typology (layout design)
Analysis the previous related studies to determine theoretical model (qualitative method)

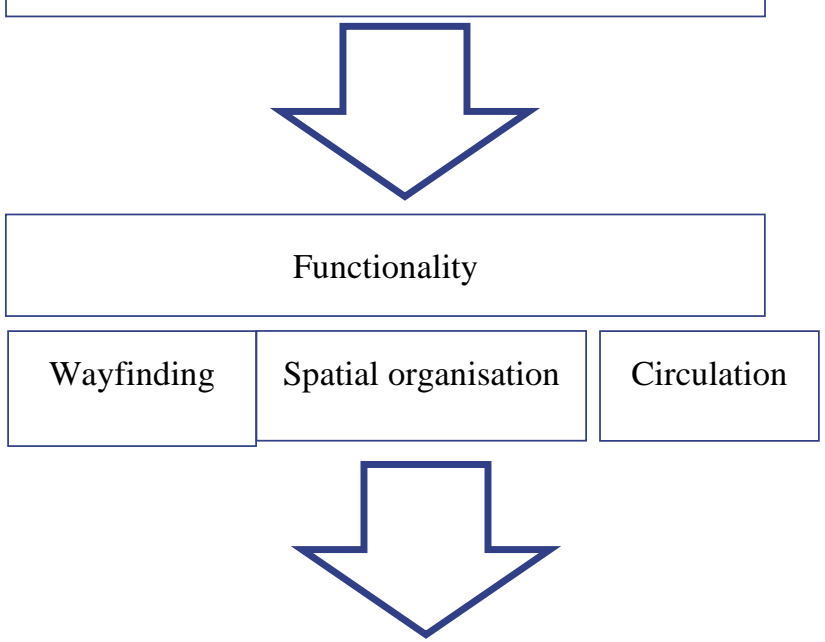

Selection of ten case study (photograph, and documentation) (Qualitative method)

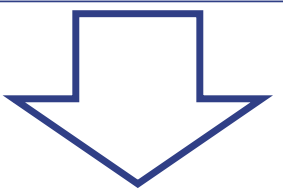

Point ,Single loaded-

corridor(Gallery),Mixed,Double loaded corridor,and large scale development(segment)

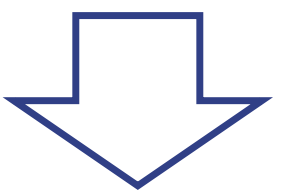

\section{Measurement tool}

Quantitative data

Depth map software

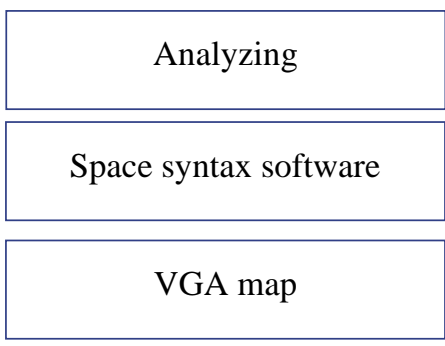

Visual Connectivity

Figure 1. Methodology stages 
Table 1. Numerical visual connectivity results of all cases study

\begin{tabular}{|c|c|c|c|c|}
\hline & \multirow{2}{*}{ Cases study } & \multicolumn{3}{|c|}{ Visual connectivity } \\
\hline & & Minimum & Average & Maximum \\
\hline \multicolumn{5}{|c|}{ Point } \\
\hline 1 & Zanyary Towers & 181 & 228 & 316 \\
\hline \multirow[t]{2}{*}{2} & Eskan Towers & 296 & 700.469 & 717 \\
\hline & Total & 239 & 464 & 517 \\
\hline \multicolumn{5}{|c|}{ Double loaded corridor } \\
\hline 3 & Cihan city type B & 132 & 442.874 & 538 \\
\hline \multirow[t]{2}{*}{4} & Park view B & 150 & 958.928 & 1179 \\
\hline & Total & 141 & 701 & 859 \\
\hline \multicolumn{5}{|c|}{ Mixed } \\
\hline 5 & Empire world & 9 & 54.7907 & 83 \\
\hline \multirow[t]{2}{*}{6} & Village Lebanon type E & 187 & 570.457 & 835 \\
\hline & Total & 98 & 313 & 459 \\
\hline \multicolumn{5}{|c|}{ Large scale Development (SEGMENT) } \\
\hline 7 & Central park & 146 & 794.069 & 895 \\
\hline \multirow[t]{2}{*}{8} & MRF Quattro & 40 & 426.323 & 743 \\
\hline & Total & 93 & 610 & 819 \\
\hline \multicolumn{5}{|c|}{ Single loaded corridor (gallery) } \\
\hline 9 & Gulan tower & 134 & 1123 & 2083 \\
\hline \multirow[t]{2}{*}{10} & Mamwstyean type A & 110 & 974 & 2800 \\
\hline & Total & 122 & 1049 & 2442 \\
\hline
\end{tabular}




\subsection{Visual Connectivity results}

The connectivity attribute is defined as the number of visually connected points to other spaces. This study is used to measure the functionality parameters of physical factors in indoor apartment spaces. Accordingly, the highest value of connectivity represented the more flexible spaces than the spaces with a lower degree of connectivity. Consequently, the numerical comparison results showed that the connectivity results value among the cases study ranged between 313 -1049. Whereas the single-loaded corridor layout design has more functionality than the other types, the connectivity value was 1049. A double-loaded corridor type layout design can be considered the second functionality design among the average 701 connectivity value cases. Finally, the result of connectivity of point type, mixed type, and significant scale Development (SEGMENT) showed that they have not acceptable layout design plan in terms of functionality with 464, 313, and 610 values of connectivity, respectively, as shown in Table 2, and Figure 2.

Table 2. Summary of visual connectivity results of all cases study

\begin{tabular}{lccc}
\hline \multirow{2}{*}{$\begin{array}{l}\text { Typologies of an apart- } \\
\text { ment (layout design) }\end{array}$} & \multicolumn{3}{c}{ Visual connectivity } \\
\cline { 2 - 4 } & Minimum & Average & Maximum \\
\hline Point & 239 & 464 & 517 \\
Double loaded corridor & 141 & 701 & 859 \\
Mixed & 98 & 313 & 459 \\
Large scale Development & 93 & 610 & 819 \\
Single loaded corridor & 122 & 1049 & 2442 \\
\hline
\end{tabular}

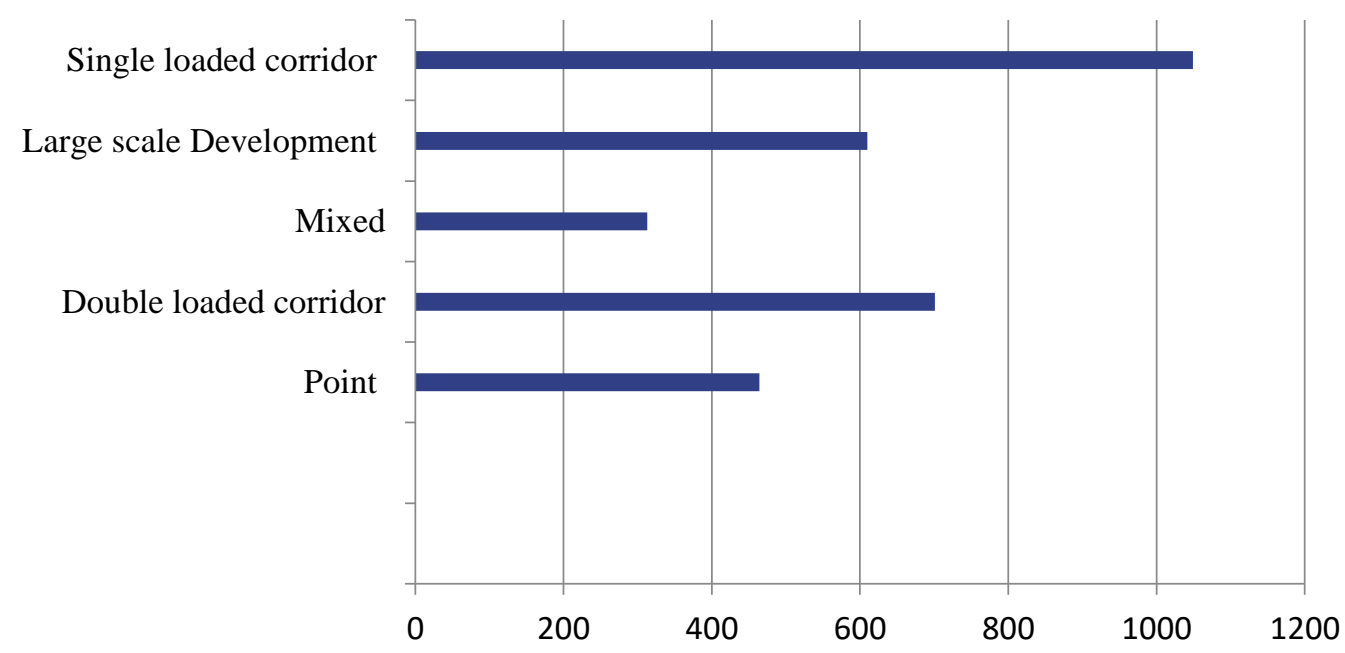

Figure 2. Comparison of functionality parameters average among the case studies 


\section{Point}
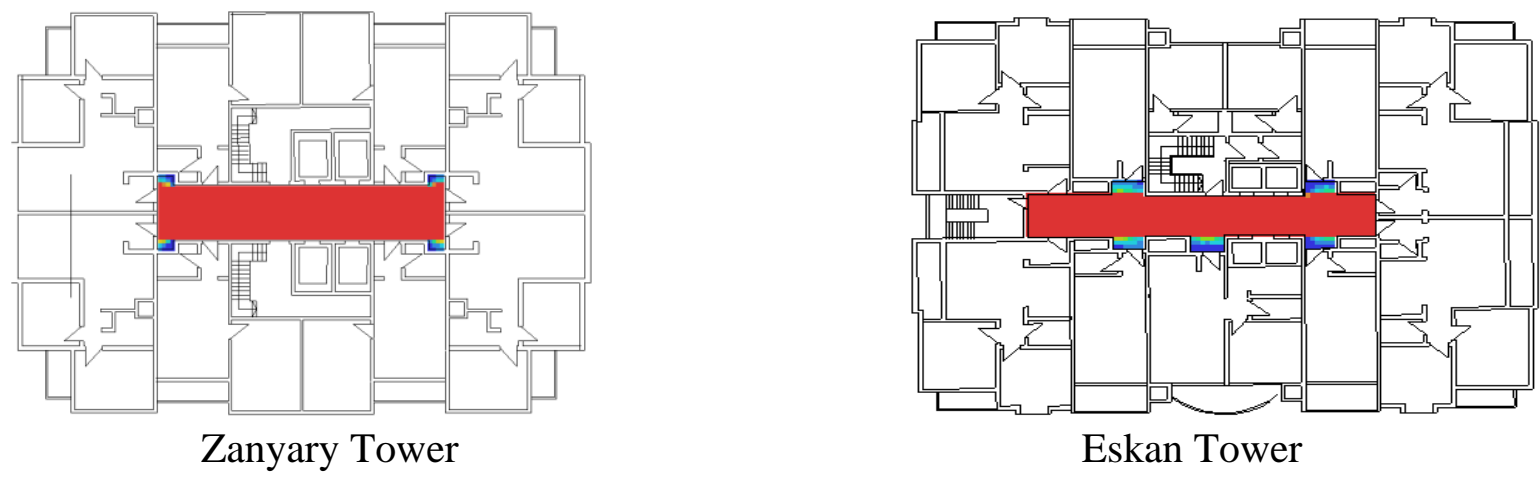

Eskan Tower

Double loaded corridor

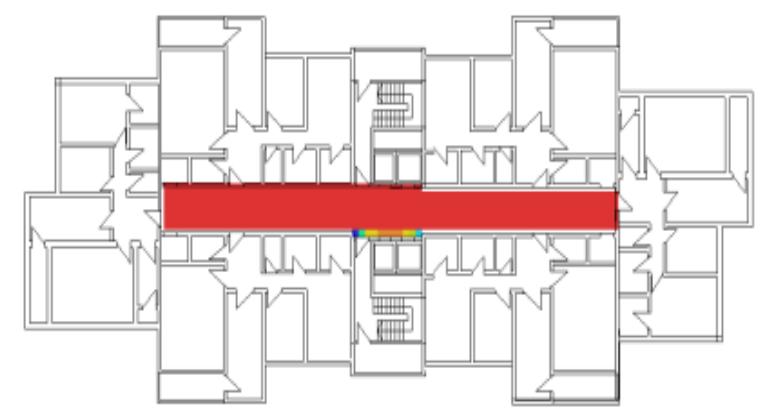

Cihan city type B

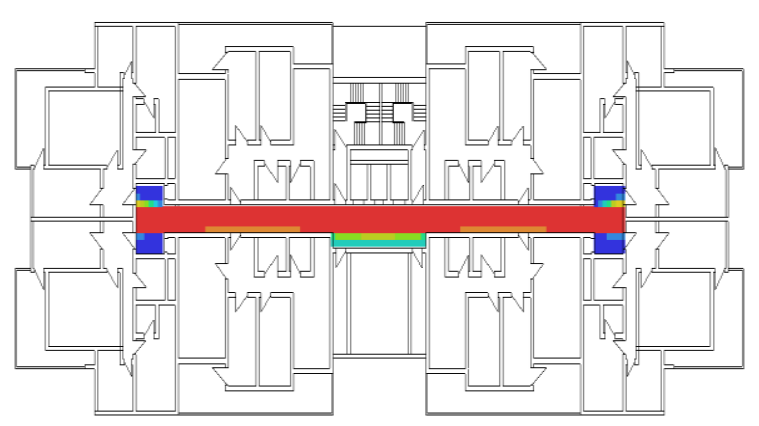

Park view type B

\section{Mixed}

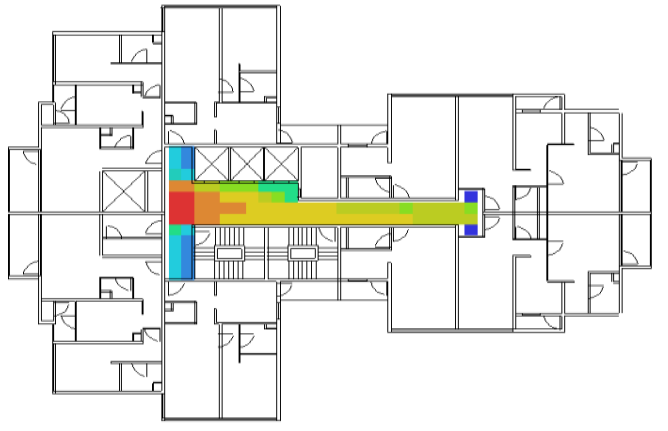

Empire World

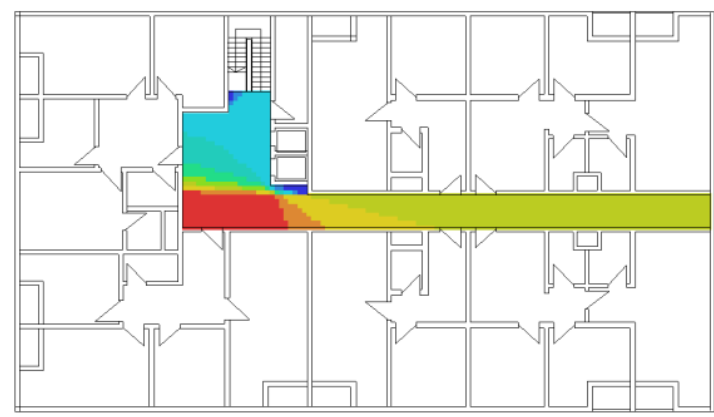

Village Lebanon type E

Large scaleDevelopment (SEGMENT)

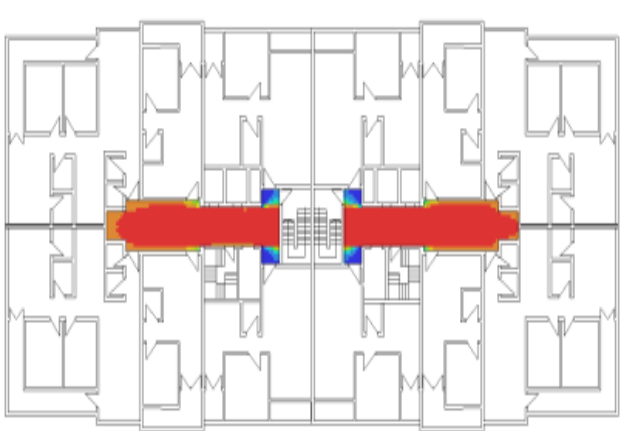

Central park

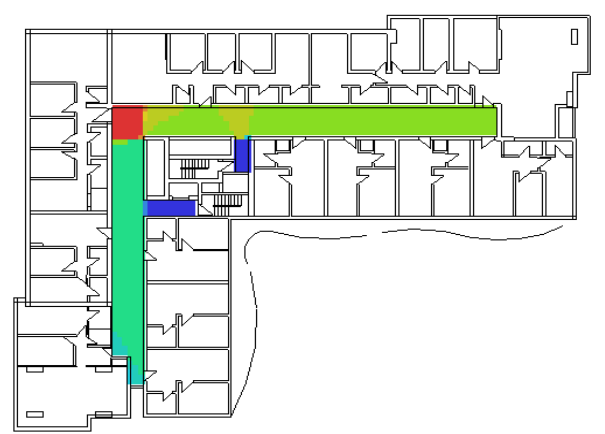

MRF Quattro 


\section{Single loaded corridor (gallery)}

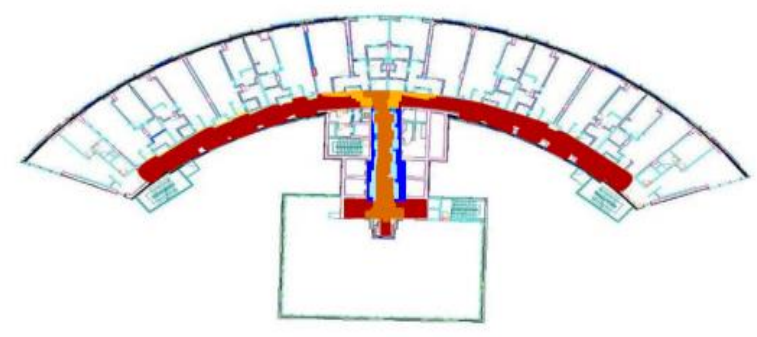

Golan Tower

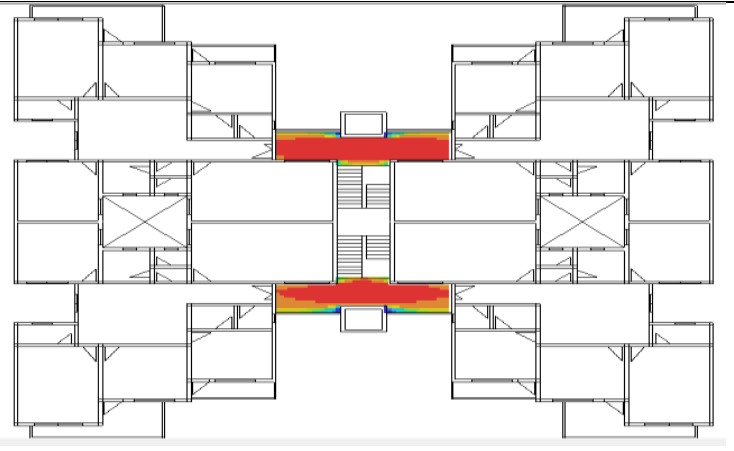

Mamwstyean type A

Figure 3. Graphs of visual connectivity analysis for ten cases study plan

The examination of the color map of the visibility graph indicates that the highest degree of visual connectivity is represented in a red color concentrated around the apartment's corridor, as shown in figure 3. The spaces with the lowest visual access are illustrated in a blue color located around the corridor. The single-loaded corridor layout design graphs showed that the corridor area has the most visual connectivity than the other types. At the same time, the layout design graph of each mixed and point type showed that the corridor space areas have low visual connectivity. The result suggested that the single-loaded corridor apartment layout design is more functionality than the other types. However, the design type of Double loaded corridor affects increasing the functionality of apartment spaces.

\section{Conclusions}

In this study, Typical floor plans for operative circulation, wayfinding, and spatial organization within the building are complex and challenging tasks of extreme significance in architectural design. Thus, the design of apartment buildings built conferring to operative circulation systems and types shows a significant role in enabling occupants to reach a comfortable life and offer better lifestyle conditions.

The connectivity attribute represented the functionality parameters. The result determined that the layout design of the apartment space influences the social distancing of areas. The single-loaded corridor type had the highest connectivity. At the same time, the Mixed type layout design had the lowest connectivity. The study concluded that the higher degree of connectedness between spaces increases functionality and encouragement to use of the area for multifunctionality.

Declaration of Competing Interest: The authors declare that they have no known competing of interest. 


\section{References}

[1] Brandt, J. and Vejre, H., 2004. Multifunctional landscapes-motives, concepts and perceptions. In Multifunctional Landscapes: Volume 1 Theory, Values and History (pp. 3-32). WIT press, Southampton, USA.

[2] Mahfuz, E., 2003. Reflexões sobre a construção da forma pertinente. Seminário Nacional sobre Ensino e Pesquisa em Projeto de Arquitetura - PROJETAR 2003, pp. 1-23.

[3] Zimring, C. and Craig, D.L., 2001. Defining design between domains: an argument for design research á la carte. In Design knowing and learning: Cognition in design education (pp. 125-146). Elsevier Science, New York, USA.

[4] Trethewy, R.W. and Atkinson, M., 2003. Enhanced safety, health and environment outcomes through improved design. Journal of Engineering, Design and Technology. 1(2), pp: 187-201

[5] Natapov, A., Kuliga, S., Dalton, R.C. and Hölscher, C., 2020. Linking building-circulation typology and wayfinding: design, spatial analysis, and anticipated wayfinding difficulty of circulation types. Architectural Science Review, 63(1), pp.34-46.

[6] Yang, B., Fu, X., Sidiropoulos, N.D. and Hong, M., 2017, July. Towards k-means-friendly spaces: Simultaneous deep learning and clustering. In international conference on machine learning. Sydney, Australia, 2017, Vol. 70, pp. 3861-3870.

[7] Hillier, B., 2007. Space is the machine: a configurational theory of architecture. Space Syntax, London, UK.

[8] O'Neill, M.J., 1991. Effects of signage and floor plan configuration on wayfinding accuracy. Environment and behavior, 23(5), pp.553-574.

[9] O'Neill, M.J., 1991. Evaluation of a conceptual model of architectural legibility. Environment and Behavior, 23(3), pp.259284.

[10] Gärling, T., Lindberg, E., Carreiras, M. and Anders, B., 1986. Reference systems in cognitive maps. Journal of Environmental Psychology, 6(1), pp.1-18.

[11] Gärling, T., Lindberg, E. and Mäntylä, T., 1983. Orientation in buildings: Effects of familiarity, visual access, and orientation aids. Journal of Applied Psychology, 68(1), p.177-186.

[12] Weisman, J., 1981. Evaluating architectural legibility: Way-finding in the built environment. Environment and behavior, 13(2), pp.189-204.

[13] Roux, 2014. What is Wayfinding?. Available at: https://segd.org/what-wayfinding (Accessed: 1 August 2021).

[14] Ching, F.D., Jarzombek, M.M. and Prakash, V., 2017. A global history of architecture. John Wiley \& Sons, Hoboken, USA.

[15] Kunjir, A.R. and Patil, K.R., 2020. Effectiveness of Practicing Social Distancing in Museums and Art Galleries for Visitors Using Mobile Augmented Reality (MAR): SMART - Social Distancing Using Mobile Augmented Reality Technology. International Journal of Art, Culture and Design Technologies (IJACDT), 9(1), pp.1-14.

[16] Krishnankutty, P., 2020. 1m, 1.5m, 2m — the different levels of social distancing countries are following amid Covid. Available at: https://theprint.in/theprint-essential/1m-1-5m-2m-the-different-levels-of-social-distancing-countries-are-followingamid-covid/449425/ (Accessed: 20 August 2021).

[17] Bapir, S.Y. and Kareem, S.M., 2021. How to Limit the Spread of COVID-19 in Residential Buildings: Erbil city as a case study. Design Engineering, 2021(7), pp.2635-2647.

[18] Majeed, M.N., Mustafa, F.A. and Husein, H.A., 2019. Impact of building typology on daylight optimization using building information modeling: Apartments in Erbil city as a case study. Journal of Daylighting, 6(2), pp.187-201. 